\title{
Videodensitometric analysis of advanced carotid plaque: correlation with MMP-9 and TIMP-1 expression
}

\author{
Liz Andréa V Baroncini ${ }^{1 *}$, Antonio Filho Pazin², Luiz Otávio Murta Junior ${ }^{3}$, Lia S Nakao ${ }^{4}$, Simone G Ramos ${ }^{5}$ and \\ Dalton B Précoma'
}

\begin{abstract}
Background: Matrix metalloproteinase-9 (MMP-9) and tissue inhibitor of MMP (TIMP) promote derangement of the extracellular matrix, which is ultimately reflected in plaque images seen on ultrasound. Videodensitometry can identify structural disturbances in plaques.

Objectives: To establish the correlations between values determined using videodensitometry in B-mode ultrasound images of advanced carotid plaques and the total expression of MMP-9 and TIMP-1 in these removed plaques.

Methods: Thirty patients underwent ultrasonic tissue characterization of carotid plaques before surgery, using mean gray level (MGL), energy, entropy and homogeneity. Each patient was assigned preoperatively to one of 2 groups: group I, symptomatic patients ( $n=16 ; 12$ males; mean age $66.7 \pm 6.8$ years), and group II, asymptomatic patients ( $n=14 ; 8$ males; mean age $67.6 \pm 6.81$ years). Tissue specimens were analyzed for MMP-9 and TIMP-1 expression. Nine carotid arteries were used as normal tissue controls.

Results: MMP-9 expression levels were elevated in group II and in normal tissues compared to group I $(p<0.001)$. TIMP-1 levels were higher in group II than in group I, and significantly higher in normal tissues than in group I $(p=$ 0.039). The MGL was higher in group II compared to group I $(p=0.038)$. Energy had greater values in group II compared to group I $(p=0.02)$. There were no differences between patient groups in homogeneity and entropy. Energy positively correlated with MMP-9 and TIMP-1 expression ( $p=0.012$ and $p=0.031$ respectively). Homogeneity positively correlated with MMP-9 and TIMP-1 expression ( $p=0.034$ and $p=0.047$ respectively). There were no correlations between protein expression and MGL or entropy.
\end{abstract}

Conclusions: Videodensitometric computer analysis of ultrasound scanning images can be used to identify stable carotid plaques, which have higher total expression levels of MMP-9 and TIMP-1 than unstable plaques.

Keywords: carotid arteries, atherosclerosis, ultrasound tissue characterization

\section{Background}

Advanced carotid plaques are complex structures, and their classification remains a challenging problem. It is not currently possible to predict whether a carotid plaque will produce symptoms or when symptoms will occur [1]. The American Heart Association classification of human

\footnotetext{
* Correspondence: lizandreabaroncini@hotmail.com

'Department of Health and Scienses - Pontificia Universidade Católica do Paraná, Rua Imaculada Conceição 1155, Curitiba, Paraná, CEP: 80215901, Brazil

Full list of author information is available at the end of the article
}

atherosclerotic lesions considers the presence or absence of different tissue components in plaques, but does not account for the proportion of each component or its location in the plaques [2]. Because plaques are dynamic structures, changing through processes of stabilization and destabilization, the locations and the proportions of different plaque components are constantly being modified. Matrix metalloproteinase 9 (MMP-9) and tissue inhibitor of MMP (TIMP-1), which are secreted by infiltrating macrophages and smooth muscle cells, are present in all stages of atherosclerotic plaque progression,

\section{() Biomed Central}


from normal tissue to advanced lesions, and are factors involved in plaque remodeling. These proteins promote the derangement of extracellular matrix, which is ultimately reflected in plaque images seen on Doppler ultrasound $[3,4]$. Carotid plaques evaluated by ultrasound are usually described in terms of echogenicity, homogeneity, board regularity, ulceration, localization, extension, and the degree of stenosis. The final decision for surgical intervention is primarily based on the degree of plaque stenosis and on the patient symptoms. Previous studies have attempted to correlate the histological composition of surgically removed carotid plaques and their ultrasonic characteristics as determined by presurgical bidimensional imaging [5-8]. In a previous study from our laboratory, we were able to use videodensitometry to correlate the echogenicity of carotid images with the fibrous tissue and lipid components of removed specimens [9]. We established that the first order parameter mean gray level determined from videodensitometric computer analysis of scan images may be used to identify vulnerable and potentially unstable lipid-rich carotid plaques, which are less echogenic in density than stable or asymptomatic, more densely fibrotic plaques. In that same study, we were able to differentiate stable from vulnerable plaques based on second-order parameter energy, although there were no correlation with the amounts of fibrous tissue or lipid components. We believe that videodensitometric second order parameters may be useful in identifying structural derangements in plaques, including inflammatory processes and disrupted extracellular matrix, that are modulated by matrix metalloproteinases and their inhibitors. We choose MMP-9 and TIMP-1 as markers of structural derangement in order to evaluate matrix remodeling in surgically removed carotid plaques. These proteins have been well studied and their role in plaque destabilization has been established. The objectives of the present study were to correlate the results of statistical analysis of videodensitometric parameters with MMP-9 and TIMP-1 expression levels in advanced carotid plaques.

\section{Methods}

\section{A. Patients}

Thirty nonconsecutive surgical inpatients (20 males, mean age $68.03 \pm 7.3$ years) admitted for carotid endarterectomy for extracranial high-grade $\left({ }^{3} 70 \%\right)$ internal carotid artery stenosis were selected for this study. The only inclusion criterion was that the patient should be already scheduled for surgery based on the degree of carotid stenosis and the presence of symptoms. If the patient was asymptomatic with stenosis $>70 \%$, the indication for surgical therapy depended on comorbidities and vertebro-basilar (in)sufficiency. Exclusion criteria were the presence of suboptimal ultrasonographic visualization of the atherosclerotic plaque contour/border, or surgical specimen inadequate for immunocytochemical analysis. Institutional ethical committee approval was obtained for the study and for procurement of specimens. Written informed consents were obtained from all patients. A clinical history and examination were performed which included a neurological exam to establish the number and duration of ischemic events. Before surgery, all patients underwent the following: (1) either cerebral angiography or magnetic resonance angiography plus Duplex ultrasound to grade carotid artery stenosis and assess the intracranial arterial system; and (2) either computed tomography $(\mathrm{CT})$ or magnetic resonance imaging (MRI) to examine the brain. The presence or absence of infarction in the corresponding middle cerebral artery territory was noted. Focal cerebral ischemic events were identified as transient ischemic attack (TIA), amaurosis fugax (AF), central retinal artery occlusion, or cerebrovascular accident. Patients were considered to be symptomatic if they had experienced AF, TIA, or stroke ipsilateral to the carotid lesion being studied. Patients without any history of recent neurologic symptoms or with nonspecific, nonhemispheric symptoms such as dizziness and vertigo were considered asymptomatic. Each patient was assigned preoperatively to one of 2 groups based on symptoms: group I consisted of symptomatic patients ( $\mathrm{n}=16 ; 12$ males; mean age $66.7 \pm 6.8$ years), and group II consisted of asymptomatic patients ( $\mathrm{n}=14 ; 8$ males; mean age $67.6 \pm 6.81$ years). Baseline determination of each patient consisted of the following: height, weight, body mass index, blood pressure, fasting serum total cholesterol (TC), high density lipoprotein cholesterol (HDL-C), low density lipoprotein cholesterol (LDL-C), triglycerides (TGC), fasting plasma glucose, electrocardiogram, and information regarding history of coronary artery disease, diabetes mellitus, and smoking habits. There were no substantial differences between the 2 patient study groups in percent reduction of carotid diameter, procedural surgical methods, concomitant therapy, age, sex, and risk factors (Table 1).

\section{B. Tissue specimens and immunoblotting}

Carotid plaques were obtained immediately after endarterectomy. All surgeries were performed using standard surgical techniques and with minimal manipulation of the specimen. All plaques were removed en bloc, without fragmentation or significant distortion. Sections used for MMP-9 and TIMP-1 quantification were snap-frozen in liquid nitrogen and stored at $-70^{\circ} \mathrm{C}$ until processing. The protein expression levels of MMP-9 and TIMP-1 in tissue extracts were analyzed by immunoblotting following sodium dodecyl sulfate polyacrylamide gel electrophoresis (SDS-PAGE). Specific regions of each plaque were not preselected for this analysis. The section was analyzed entirely, as described previously [2]. Briefly, carotid 
Table 1 Baseline patient characteristics

\begin{tabular}{lll}
\hline & $\begin{array}{l}\text { Group I } \\
(\mathbf{n}=\mathbf{1 6})\end{array}$ & $\begin{array}{l}\text { Group II } \\
(\mathbf{n}=\mathbf{1 4})\end{array}$ \\
\hline Age, years & $66.7 \pm 6.8$ & $67.6 \pm 6.8$ \\
Sex, M/F & $12 / 4$ & $8 / 6$ \\
Hypertension & 10 & 1 \\
Diabetes Mellitus & 2 & 3 \\
Active smoking & 3 & 3 \\
Hypercholesterolemia & 2 & 1 \\
CAD & 4 & 0 \\
Aspirin & 15 & 10 \\
Statin & 5 & 4 \\
ACE inhibitors & 9 & 8 \\
Ticlopidine & 4 & 1 \\
\hline
\end{tabular}

samples $(\mathrm{n}=30)$ were minced and homogenized in lysis buffer containing PBS (pH 7.2), 0.5\% Triton X-100, 0.1\% SDS, $0.5 \%$ sodium deoxycholate, and a protease inhibitor cocktail (Roche) at $4^{\circ} \mathrm{C}$. The extracts were centrifuged (5000 rpm, $15 \mathrm{~min}, 4^{\circ} \mathrm{C}$ ), and supernatants were collected and stored at $-20^{\circ} \mathrm{C}$ until analysis. Total protein concentrations in the lysates were determined using the Bradford protein assay. Proteins $(10 \mu \mathrm{g})$ were separated through a $10 \%$ acrylamide/bisacrylamide SDS gel and transferred to a nitrocellulose membrane. After incubation in nonfat milk, membranes were probed with antiMMP (1:1000), or anti-TIMP-1 (1: 50) antibodies (Santa Cruz Biotechnology), followed by incubation in secondary antibodies conjugated to horseradish peroxidase (HRP). Reactions were developed using SuperSignal WestPico Chemiluminescent Substrate (Thermo Fisher Scientific Inc., Rockford, IL, USA). For endogenous controls, membranes were also probed with anti- $\beta$ actin (1:5000; Sigma-Aldrich, St. Louis, MO, USA) and antimouse IgG conjugated to HRP (KLP 1:2000; Kirkegaard and Perry Laboratories, Gaithersburg, MD, USA). Densitometry analysis was performed using ImageJ software. Nine carotid arteries were removed from human adult cadavers that had not been preselected for carotid artery disease. These specimens did not have any macroscopic signs of atherosclerotic plaques and were used as normal tissue controls.

\section{Ultrasonographic Image Acquisition and Preprocessing} Ultrasound assessment was performed 1 to 2 days before carotid endarterectomy. Conventional echo images were acquired with a commercially available $2 \mathrm{D}$ ultrasonic imaging system (Hewlett-Packard Sonos 5500; Andover, MA, USA). The system characterized arterial tissue at the bedside using a 5 - to $12-\mathrm{MHz}$ multifrequency linear transducer for all studies. This software enables the acquisition, storage, and retrieval of a sequence of continuous $2 \mathrm{D}$ conventional images, forming a continuous-loop digital recording of $2 \mathrm{~s}$ (60 frames per $2 \mathrm{~s}$ ). Anterior, lateral, and posterior projections were used to image the plaque longitudinally. The position of the probe was adjusted so that the ultrasonic beam was vertical to the artery wall. Offline analysis of the $2 \mathrm{D}$ images was performed after retrieving the stored data from the built-in optical disc drive in the system. For videodensitometric analysis, the images from the magnetic optical disk were loaded into a computer installed with a specific software program (CaPAS - Carotid Plaque Analysis Software; University of Sao Paulo, Sao Paulo, Brazil). Subjective selection was performed to optimize the contours/borders, area, and contrast of each plaque. Selected static frames considered appropriate for analysis fulfilled the following criteria: 1) blood in the vicinity of the plaques was dark and echoically uniform, and 2) the atherosclerotic plaque was well delineated, horizontal, and of maximum thickness.

\section{E. Quantitative texture analysis}

All plaque images were evaluated by CaPAS software for texture parameters, which include a set of first-order (mean gray level) and of second-order (entropy, energy, and homogeneity) parameters. These parameters were described in a previous study [9]. Briefly, the mean gray level (MGL) represented the median of the frequency distribution of gray tones of the pixels included in the region of interest (ROI) (gray-scale median of the region) for a scale of 256 gray tones $(0=$ darkest tone, $255=$ brightest tone) [10]. Dark (hypoechoic) regions were associated with a gray-scale median (GSM) that tended to approach 0 , whereas bright (hyperechoic) regions were associated with a GSM that tended to approach 255. The energy or angular second-moment value increases when elements in the co-occurrence matrix are very unequal. Entropy and homogeneity reflect the degree of coarseness of the image, as its value increases when homogeneity is reduced; i.e., when elements in the co-occurrence matrix tend to be equal and the diagonal concentration lowers. The mathematical definitions of these texture parameters have been described in a previous article [8]. Plaque images were normalized using 2 echo-anatomic reference points: the GSM of the blood and the GSM of the periadventitial region. After normalization, each image was manually outlined in its longitudinal section 3 times by the same examiner. The mean score of these 3 sequential measurements was used for analysis (Figures 1 and 2). Examiner performing the ultrasonography and outlining the images was blinded to the results of immunohistochemical analysis.

\section{Statistical analysis}

Categorical variables were expressed as percentages, and continuous variables were expressed as means \pm SD and medians. The Shapiro-Wilk test was used to evaluate 


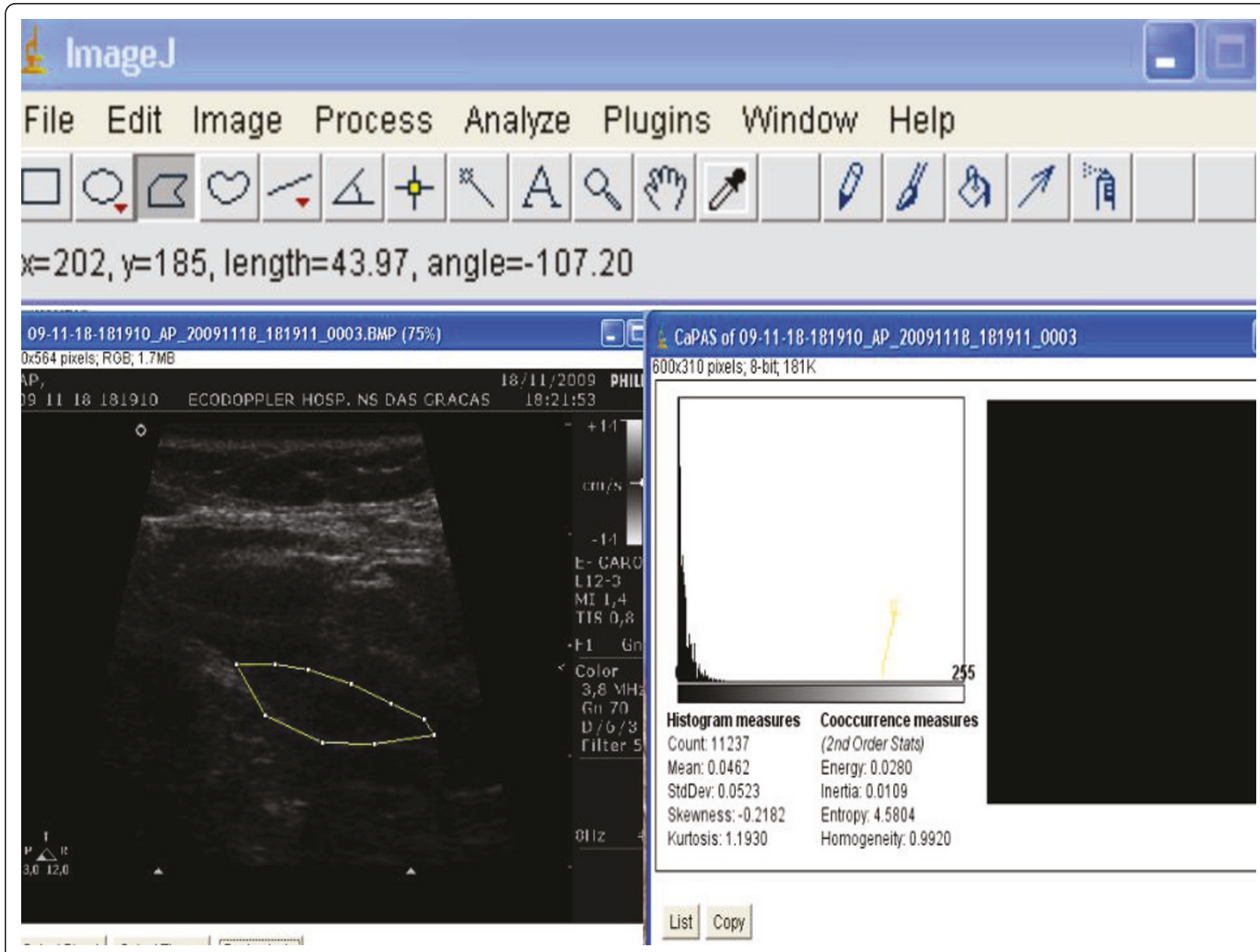

Figure 1 Hypoechoic (lipid) carotid plaque and CaPAS analyzes. Left panel: bidimensional image of carotid plaque. Right panel: CaPAS parameters.

sample normality. For quantitative parameters, the Mann-Whitney nonparametric test was used to compare groups. The Spearman coefficient was used to identify correlations between quantitative variables. Statistical significance was indicated by a value of $p<0.05$. Analyses were performed using Statistica v. 8.0. Intra- and interexaminer variabilities in ultrasonographic measurements were tested for all carotid images as proposed by Lin [10].

\section{Results}

\section{A. Expression of MMP-9 and TIMP-1}

MMP-9 expression was significantly elevated in group II and in normal tissues compared to group I ( $\mathrm{p}<0.001$ ). TIMP-1 levels were higher in group II and in normal tissues than in group I, with statistical difference between normal tissue and GI ( $\mathrm{p}=0.039$; Table 2).

\section{B. Videodensitometric Analysis}

Among first order-parameters, MGL had higher values in group II ( $\mathrm{p}=0.038)$. Among second order-parameters, energy distinguished group I from group II with higher values in group II $(p=0.012)$. There were no significant differences for homogeneity and entropy between groups (Table 3).

\section{Correlation Between Immunoblotting and Videodensitometric Analysis}

Energy, a second-order parameter, positively correlated with MMP-9 and TIMP-1 expression ( $\mathrm{p}=0.012$ and $\mathrm{p}=$ 0.031 respectively). Homogeneity, a second-order parameter, also positively correlated with MMP-9 and TIMP1 expression ( $\mathrm{p}=0.034$ and $\mathrm{p}=0.047$ respectively). There was no statistically significant correlation between MGL or entropy and protein expression levels (Table 4; Figures 3 and 4).

\section{Discussion}

The ultrasound imaging description of a plaque requires more than reporting the degree of stenosis. In evaluating the echogenicity of a carotid plaque, the ultrasonographer 


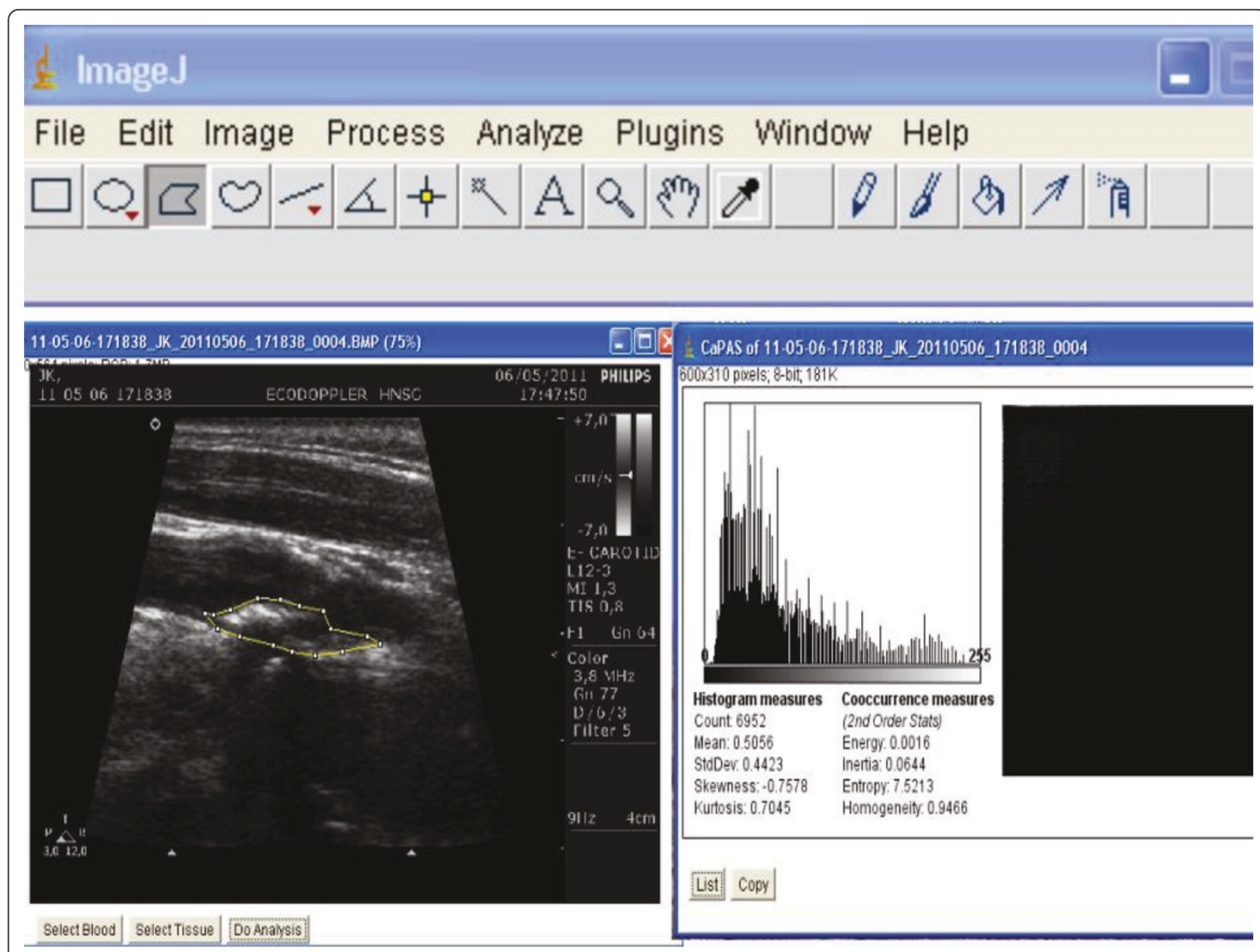

Figure 2 Hyperechoic (fibrotic) carotid plaque and CaPAS analyzes. Left panel: bidimensional image of carotid plaque. Right panel: CaPAS parameters.

visualizes the plaque as a unique structure, and s/he can only subjectively determine its characteristics in general terms (i.e., hypoechoic or hyperechoic, heterogeneous or homogeneous). These characteristics are too subjective for daily clinical practice and are affected by the training and experience of the ultrasonographer. Despite advances in duplex ultrasound scanning technology, the process of

Table 2 MMP-9 and TIMP-1 expression (in arbitrary units of band densitometry, normalized by $\beta$-actin expression), in the study groups

\begin{tabular}{llllll}
\hline Variable & Group & Mean & Median & SD & p value \\
\hline MMP-9 & Gl & 127 & 147 & 44.3 & \\
& GII & 198.9 & 201.3 & 11.5 & $<0.001$ \\
& Control & 182.1 & 181 & 25.2 & \\
TIMP-1 & Gl & 1.2 & 0 & 1.8 & \\
& GII & 2.1 & 2.1 & 1.8 & 0.039 \\
& Control & 3.6 & 2.4 & 2.7 & \\
\hline
\end{tabular}

MMP-9 means metalloproteinase-9.

TIMP-1 means tissue inhibitor of metalloproteinase-1. acquiring, analyzing, and interpreting B-mode images has remained observer-dependent. Because various classifications have relied on the human observer rather than objective measurements, there has been great variability in the incidence of cerebrovascular events in relation to plaque morphology. A previous investigation [11] based on the

Table 3 Comparisons of videodensitometric parameters between groups I and II

\begin{tabular}{llccccc}
\hline Variables & & N & Mean & Median & SD & p-value* \\
\hline MGL & Gl & 16 & 0.390 & 0.400 & 0.126 & \\
Entropy & Gll & 14 & 0.505 & 0.556 & 0.159 & $\mathbf{0 . 0 3 8}$ \\
& Gl & 16 & 5.676 & 5.706 & 0.390 & \\
Energy & Gll & 14 & 5.531 & 5.636 & 0.496 & 0.423 \\
& Gl & 16 & 0.006 & 0.005 & 0.004 & \\
Homogeneity & Gll & 14 & 0.024 & 0.010 & 0.028 & $\mathbf{0 . 0 1 2}$ \\
& Gll & 16 & 0.201 & 0.195 & 0.043 & \\
\end{tabular}

* Mann-Whitney non-parametric test, $p<0,05$ considered significant. 
Table 4 Correlations between protein expressions levels and videodensitometric parameters

\begin{tabular}{lllcc}
\hline Variable & & $\mathbf{n}$ & Correlation coefficient & $\mathbf{p}$ value \\
\hline MMP-9 versus & MGL & 30 & 0.18 & 0.357 \\
& Entropy & 30 & -0.30 & 0.133 \\
& Energy & 30 & 0.48 & $\mathbf{0 . 0 1 2}$ \\
\multirow{4}{*}{ TIMP-1 versus } & Homogeneity & 30 & 0.41 & $\mathbf{0 . 0 3 4}$ \\
& EGL & 30 & 0.10 & 0.638 \\
& Entropy & 30 & -0.34 & 0.102 \\
& Energy & 30 & 0.44 & $\mathbf{0 . 0 3 1}$ \\
& Homogeneity & 30 & 0.41 & $\mathbf{0 . 0 4 7}$ \\
\hline
\end{tabular}

appearance of radiofrequency signal determined that the echo coming from the transition between the intima-media arterial wall was of relatively low amplitude in normal and fatty samples compared to others pathologic subsets. This pioneering study from Picano et al. has been a great contribution to the field of ultrasound image analysis and image correlation with different tissues. Therefore, correlating plaque proteins expression with ultrasonic textural characteristics of carotid plaques based on videodensitometry, may be a noninvasive quantitative method for the identification of vulnerable carotid plaques. The videodensitometric method analyzes the echogenic and ultrasonic characteristics of the entire image selected. It reports the parameters obtained from the analyses of the entire selected image and can assess the extent of structural disorder represented by the image. In the present study, we correlated parameters from videodensitometric analyses with protein expression in plaques. In our previous study [2], we determined that expression levels of MMP-9 and TIMP-1 were higher in surgical specimens from asymptomatic patients, which corresponded to more stable chronic plaques. In that study, the entire section of plaque was analyzed and the total expression of each protein was determined. Another study [12] has corroborated these findings, and the authors speculated that a certain baseline level of metalloproteinase activity is necessary for the maintenance of a stable carotid plaque. Therefore, in the present study, we assessed the videodensitometric parameters acquired from the total imaging depicted and correlated them with the results from the entire section of plaque that was analyzed. We found positive correlations for MGL, homogeneity, and energy with expressions levels of MMP9 and TIMP-1. Among first-order parameters, MGL assess overall contrast and the echodensity of an image and correlate well with stable or fibrotic and calcified carotid plaques [8,13-24]. First-order statistical parameters are mathematical descriptors of the shape of the frequency distribution of a gray-level histogram, and are used to describe the overall brightness of the ROI. Classically, they correlate with structural tissue components based on attenuation of the ultrasound beam, and represent the intensity of image brightness without determining regional variations in the plaque. The second-order parameters are associated with patterns of texture, and depend less on the intensity of brightness and more on heterogeneity of the image. They are mathematical descriptors of the spatial distribution and dependence of gray levels within the ROI. They are based on a co-occurrence matrix that estimates the probability that a pair of pixels, each with its own gray level and separated by a displacement vector, occurs in the considered ROI. The second-order parameters do not indicate the amount of a specific tissue component, but how it is arranged and organised spatially. Therefore, in the present study, we attempted to correlate images derangements to protein expression levels. In that sense, the metalloproteinases are involved in the remodelling processes of the plaque [25-31]. According to our findings, MMP-9 and
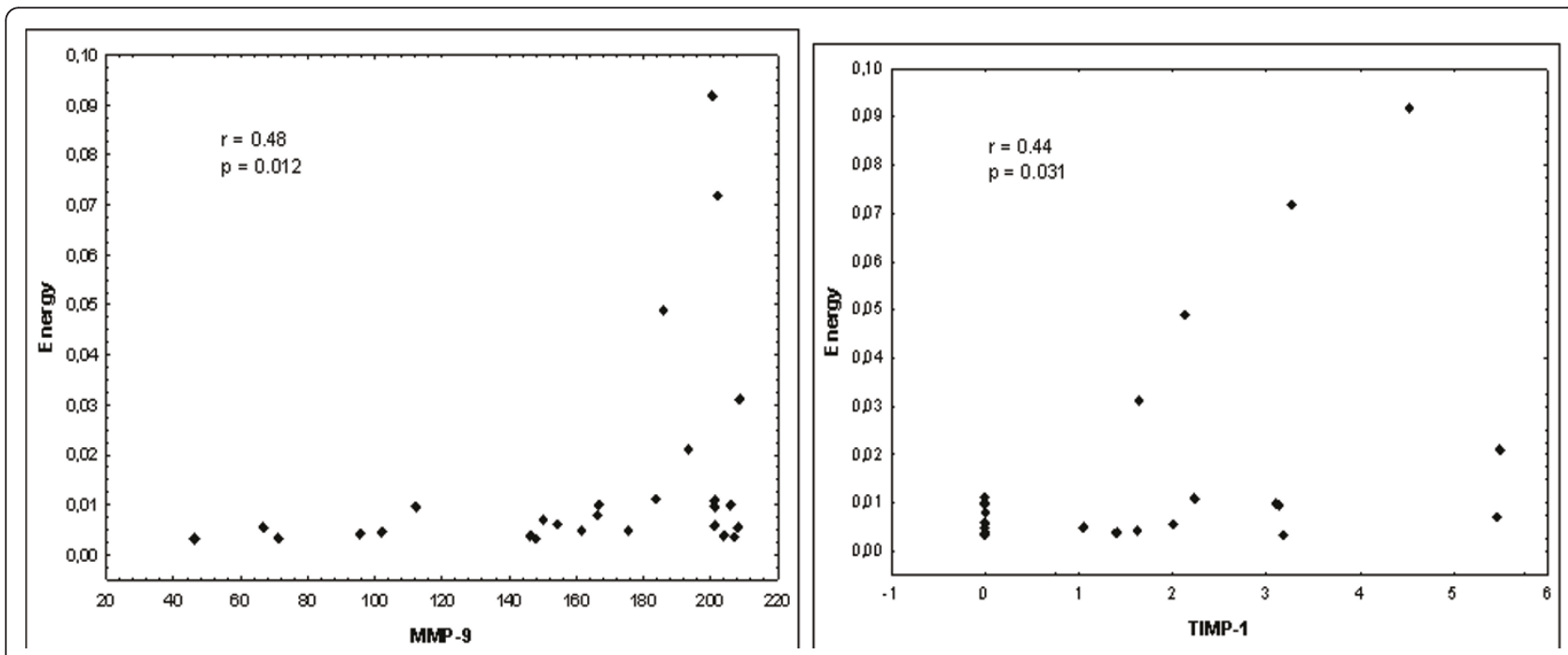

Figure 3 Correlations between protein expressions levels and energy parameters. 

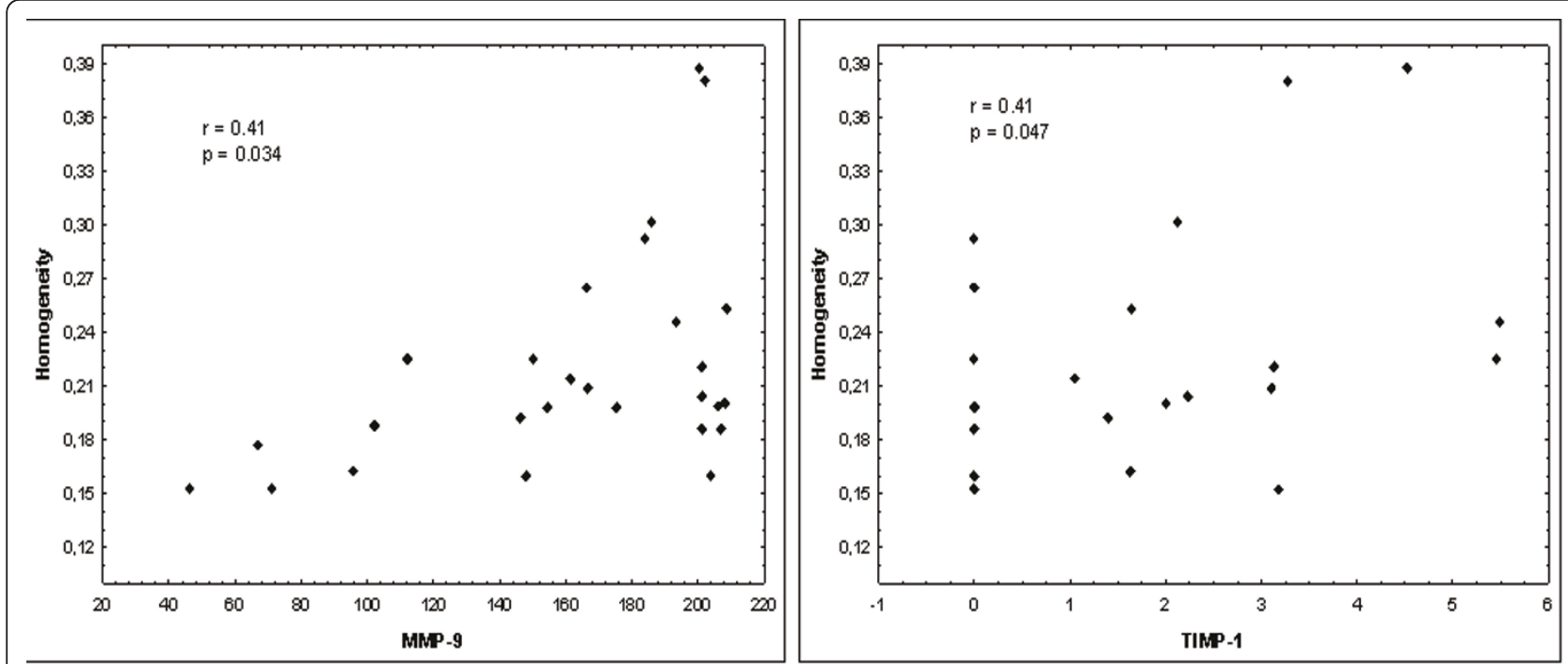

Figure 4 Correlations between protein expressions levels and homogeneity parameters.

TIMP-1 were expressed at higher levels in normal tissues and in surgical specimens from asymptomatic patients than in specimens from symptomatic patients. Secreted by macrophages and smooth muscle cells in attempts to stabilize the plaque, MMP-9 and TIMP-1 derange the extracellular matrix and cause imbalances. Finally, attempting to correlate videodensitometric parameters with specific regions inside the plaques, such as regions with increased concentrations of inflammatory cells or highly vulnerable regions like the shoulder of a plaque, does not seem to be feasible. At the present time, it is not possible to use bidimensional imaging to select a specific region in the image and correlate that with immunohistochemical parameters. Bidimensional ultrasound produces an image of gray tone variations and it is impossible for the human eye to distinguish specific or small regions inside the plaque. While magnetic resonance (MRI) can be used to discriminate between the different stages of thrombus and hemorrhage formation, the videodensitometric approach with bidimensional images can not distinguish intra-plaque hemorrhage or classify plaque subtypes [32,33]. Therefore, we assessed the image of an entire plaque and attempted to correlate with the entire section of the surgically removed plaque. Based on our results, plaques identified in bidimensional images as having higher energy values and greater homogeneity should be more stable and less prone to rupture. Such knowledge would change the clinical approach taken to treat to the patient. Using an inexpensive method, a physician could determine whether an asymptomatic patient with a high-degree of carotid stenosis needed immediate surgical treatment. In addition, since plaques can be easily assessed using this method, they can be frequently evaluated for changes in their structure. However, the videodensitometric approach, like radiofrequency analysis, is still limited to research applications and requires time and analysis away from the echo machine. We believe that this is the first study to use this approach and that future studies are needed with more patients to corroborate our findings.

\section{Conclusions}

Videodensitometric computer analysis of ultrasound scanning images may be used to identify more stable carotid plaques, which have higher expression levels of MMP-9 and TIMP-1 than unstable plaques.

\section{Author details}

${ }^{1}$ Department of Health and Scienses - Pontificia Universidade Católica do Paraná, Rua Imaculada Conceição 1155, Curitiba, Paraná, CEP: 80215901,

Brazil. ${ }^{2}$ Division of Emergency Medicine, Faculdade de Medicina de Ribeirão Preto, USP, Rua Bernardino de Campos 1000, Ribeirão Preto, São Paulo, CEP: 14015130, Brazil. ${ }^{3}$ Department of Computer Scienses and Mathematics, FFCRP, USP, Avenida Bandeirantes 3900, Ribeirão Preto, São Paulo, CEP: 14040901, Brazil. ${ }^{4}$ Department of Basic Pathology, Universidade Federal do Paraná, Centro Politécnico, Curitiba, Paraná, CEP: 80531980, Brazil.

${ }^{5}$ Department of Pathology, Faculdade de Medicina de Ribeirão Preto, USP, Avenida Bandeirantes 3900, Ribeirão Preto, São Paulo, CEP: 14049900, Brazil.

\section{Authors' contributions}

LAVB, APF and DBP design the study and wrote the manuscript. LOMJ developed the CaPAS software. LSN and SGR analyzed the surgical specimens. All authors read and approved the final manuscript.

\section{Competing interests}

The authors declare that they have no competing interests.

Received: 9 August 2011 Accepted: 18 September 2011 Published: 18 September 2011

\section{References}

1. Hermus L, Lefrandt JD, Tio RA, Breek JC, Zeebregts CJ: Carotid plaque formation and serum biomarkers. Atherosclerosis 2010, 213:21-29.

2. Baroncini LAV, Nakao LS, Ramos SG, Pazin Filho A, Murta LO Jr, Ingberman M, Tefé-Silva C, Précoma DB: Assessment of MMP-9, TIMP-1, 
and COX-2 in normal tissue and in advanced symptomatic and asymptomatic carotid plaques. Thrombosis Journal 2011, 9:6.

3. Cipollone F, Prontera C, Pini B, Marini M, Fazia M, De Cesare D, lezzi A, Ucchino S, Boccoli G, Saba V, Chiarelli F, Cuccurullo F, Mezzetti A: Overexpression of functionally coupled cyclooxygenase- 2 and prostaglandin $\mathrm{E}$ synthase in symptomatic atherosclerotic plaques as a basis of prostaglandin $\mathrm{E}^{2}$-dependent plaque instability. Circulation 2001, 104:921-927.

4. Turu MM, Krupinski J, Catena E, Rosell A, Montaner J, Rubio F, AlvarezSabin J, Cairols M, Badimon L: Intraplaque MMP-8 level are increased in asymptomatic patients with carotid plaque progression on ultrasound. Atherosclerosis 2005, 187:161-169.

5. Geroulakos G, Ramaswami G, Nicolaides A, James K, Labropoulos N, Belcaro G, Holloway M: Characterization of symptomatic and asymptomatic carotid plaques using high-resolution real-time ultrasonography. Br J Surg 1993, 80:1274-1277.

6. Tegos TJ, Sohail M, Sabetai MM, Robless P, Akbar N, Pare G, Stansby G, Nicolaides AN: Echomorphologic and histopathologic characteristics of unstable carotid plaques. Am J Neuroradiol 2000, 21:1937-1944.

7. Sabetai MM, Tegos TJ, Nicolaides AN, Dhanjil S, Pare GJ, Stevens JM: Reproducibility of computer - quantified carotid plaque echogenicity. Can we overcome the subjectivity? Stroke 2000, 31:2189-2196.

8. Mazzone AM, Urbani MP, Picano E, Paterni M, Borgatti E, De Fabritiis A, Landini L: In vivo ultrasonic parametric imaging of carotid atherosclerotic plaque by videodensitometric technique. Angiology 1995, 46:663-672.

9. Baroncini LAV, Pazin Filho A, Murta LO Jr, Martins AR, Ramos SG, Cherri J, Piccinato CE: Ultrasonic tissue characterization of vulnerable carotid plaque: correlation between videodensitometric method and histological examination. Cardiovascular Ultrasound 2006, 4:32.

10. Lin LI: A concordance correlation coefficient to evaluate reproducibility. Biometrics 1989, 45:255-268.

11. Picano E, Landini L, Lattanzi F, Salvadori M, Benassi A, L'Abbate A: Time domain echo pattern evaluations from normal and atherosclerotic arterial walls: a study in vitro. Circulation 1988, 77:654-659.

12. Hower CD, Dassow MS, Kajdacsy-Balla A, Seabrook GR, Jean-Claude J, Towne JB, Cambria RA: Metalloproteinase levels are decreased in symptomatic carotid plaques. J Surgical Research 2000, 88:155-159.

13. Beletsky VY, Kelley RE, Fowler M, Phifer T: Ultrasound densitometric analysis of carotid plaque composition. Stroke 1996, 27:2173-2177.

14. Aly S, Bishop CC: An objective characterization of atherosclerotic lesion. An alternative method to identify unstable plaque. Stroke 2000, 31:1921-1924.

15. Lal BK, Hobson RW II, Pappas PJ, Kubicka R, Hameed M, Chakhtura EY, Jamil Z, Padberg FT Jr, Haser PB, Duran WN: Pixel distribution analysis of B - mode ultrasound scan images predicts histologic features of atherosclerotic carotid plaques. J Vasc Surg 2002, 35:1210-1217.

16. Sztajel R, Momjian S, Momjian-Mayor I, Murith N, Djebaili K, Boissar G, Comelli M, Pizolato G: Stratified gray-scale median analysis and color mapping of the carotid plaque. Correlation with endarterectomy specimen histology of 28 patients. Stroke 2005, 36:742-745.

17. Wilhjelm JE, Grønholdt MLM, Wiebe B, Jespersen SK, Hansen LK, Sillesen H: Quantitative analysis of ultrasound B-mode images of carotid atherosclerotic plaque: correlation with visual classification and histological examination. IEEE Trans Med Imag 1998, 17:910-922.

18. Biasi GM, Froio A, Diethrich EB, Deleo G, Galimberti S, Mingazzini P, Nicolaides NA, Griffin M, Raithel D, Reid DB, Valsecchi MG: Carotid plaque echolucency increases the risk of stroke in carotid stenting. The imaging in carotid angioplasty and risk of stroke (ICAROS) study. Circulation 2004, 110:756-762.

19. Gray-Weale AC, Graham JC, Burnett JR, Byrne K, Lusby RJ: Carotid artery atheroma: comparison of preoperative B-mode ultrasound appearance with carotid endarterectomy specimen pathology. J Cardiovasc Surg 1988, 29:676-681.

20. Mathiesen EB, Bonaa KH, Joakimsen O: Echolucent plaques are associated with high risk of ischemic cerebrovascular events in carotid stenosis: the tromso study. Circulation 2001, 103:2171-2175.

21. Gronholdt MLM, Nordestgaard BG, Schroeder TV, Vorstrup S, Sillesen H: Ultrasonic echolucent carotid plaques predict future strokes. Circulation 2001, 104:68-73.
22. Tegos TJ, Stavropoulos P, Sabetai MM, Khodabakhsh P, Sassano A, Nicolaides AN: Determinants of carotid plaque instability: echoicity versus heterogeneity. Eur J Vasc Endovasc Surg 2001, 22:22-30.

23. Sabetai MM, Tegos TJ, Nicolaides AN, El-Atrozy TS, Dhanjil S, Griffin M, Belcaro G, Geroulakos G: Hemispheric symptoms and carotid plaque echomorphology. J Vasc Surg 2000, 31:39-49.

24. Pedro LM, Pedro MM, Gonçalves I, Carneiro TF, Balsinha C, Fernandes e Fernandes R, Fernandes e Fernandes J: Computer -assisted carotid plaque analysis: characteristics of plaques associated with cerebrovascular symptoms and cerebral infarction. Eur J Vasc Endovasc Surg 2000, 19:118-123.

25. Higashikata T, Yamagishi M, Higashi T, Nagata I, lihara K, Miyamoto S, Ishibashi-Ueda H, Nagaya N, Iwase T, Tomoike H, Sakamoto A: Altered expression balance of matrix metalloproteinases and their inhibitors in human carotid plaque disruption: Results of quantitative tissue analysis using real-time RT-PCR method. Atherosclerosis 2006, 185:165-172.

26. Fiotti N, Moretti ME, Bussani R, Altamura N, Zamolo F, Gerloni R, Ukovich L, Ober E, Silvestri F, Grassi G, Adovasio R, Giansante C: Features of vulnerable plaques and clinical outcome of UA/NSTEMI: relationship with matrix metalloproteinase functional polymorphisms. Atherosclerosis 2011, 215:153-159.

27. Ducharme A, Frantz S, Aikawa M, Rabkin E, Lindsey M, Rhode LE, Schoen FJ, Kelly RA, Werb Z, Libby P, Lee RT: Targeted deletion of matrixmetalloproteinase-9 attenuates legt ventricular enlargement and collagen accumulation after experimental myocardial infarction. I Clin Invest 2000, 106:55-62.

28. Kunte H, Kunte G, Busch MA, Weichert W, Ruckert Rl, Harms L: Differences in carotid plaque content of macrophages, T cells and MMP-9 between patients with embolic and hemodynamic cerebral ischemia due to symptomatic carotid stenosis. Atherosclerosis 2010, 211:456-460.

29. Johnson C, Galis ZS: Matrix metalloproteinase-2 and -9 differentially regulate smooth muscle cell migration and cell-mediated collagen organization. Arterioscler Thromb Vasc Biol 2004, 24:54-60.

30. Galis ZS, Khatri JJ: Matrix metalloproteinases in vascular remodeling and atherogenesis: the good, the bad and the ugly. Circ Res 2002, 90:251-262.

31. Fiotti $N$, Xiong W, Giansante C: MMP-2 genetic variant and plaque features of instability. Atherosclerosis 2010, 210:43-44.

32. Moody AR, Murphy RE, Morgan PS, Martel Al, Delay GS, Allder $S$, MacSweeney ST, Tennant WG, Gladman J, Lowe J, Hunt BJ: Characterization of complicated carotid plaque with magnetic resonance direct thrombus imaging in patients with cerebral ischemia. Circulation 2003, 107:3047-3052.

33. Esposito L, Saam T, Heider P, Bockelbrink A, Pelisek J, Sepp D, Feurer R, Winkler C, Liebig T, Holzer K, Pauly O, Sadikovic S, Hemmer B, Poppert H: MRI plaque imaging reveals high-risk carotid plaques especially in diabetic patients irrespective of the degree of stenosis. BMC Medical Imaging 2010, 10:27.

doi:10.1186/1476-7120-9-24

Cite this article as: Baroncini et al.: Videodensitometric analysis of advanced carotid plaque: correlation with MMP-9 and TIMP-1 expression. Cardiovascular Ultrasound 2011 9:24

\section{Submit your next manuscript to BioMed Central and take full advantage of:}

- Convenient online submission

- Thorough peer review

- No space constraints or color figure charges

- Immediate publication on acceptance

- Inclusion in PubMed, CAS, Scopus and Google Scholar

- Research which is freely available for redistribution

Submit your manuscript at www.biomedcentral.com/submit
Ciomed Central 